\title{
Fabrication and characterisation of thin low-temperature MBE-compatible silicon oxides of different stoichiometry
}

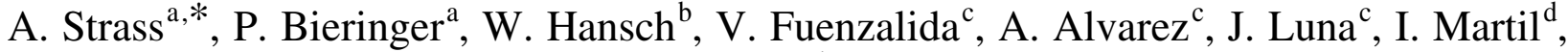 \\ F.L. Martinez ${ }^{\mathrm{d}}$, I. Eisele ${ }^{\mathrm{a}}$ \\ ${ }^{a}$ Universität der Bundeswehr München, Fakultät für Elektrotechnik, Institut für Physik, Werner-Heisenberg-Weg 39, 85579 Neubiberg, Germany \\ ${ }^{\mathrm{b}}$ Hiroshima University, Research Center for Nanodevices and Systems, 1-4-2 Kagamiyama, Higashi-Hiroshima 739, Japan \\ ${ }^{\mathrm{c}}$ Universidad de Chile, Facultad de Ciencias Fisicas y Matematicas, Departamento de Fisica, Avenida Blanco Encalada 2008, Casilla 487-3, Santiago, Chile \\ ${ }^{\mathrm{d} U n i v e r s i d a d}$ Complutense, Departamento de Fisica Aplicada III, Facultad de Ciencias Fisicas, Madrid 28040, Spain
}

Received 16 July 1998; received in revised form 11 January 1999; accepted 8 February 1999

\begin{abstract}
We developed and tested three MBE-compatible processes for the deposition of high-quality low-temperature silicon oxides and oxynitrides in the ultra high vacuum at substrate temperatures between room temperature and $500^{\circ} \mathrm{C}$ : gas enhanced evaporation (GEE), plasma enhanced evaporation (PEE) and plasma enhanced oxidation (PEO). The deposited layers were thoroughly investigated and compared with respect to their electrical, optical and stoichiometrical properties by means of ellipsometry, mechanical profilometry, Auger electron spectroscopy (AES), X-ray photoelectron spectroscopy (XPS), Rutherford backscattering (RBS), Fourier transform infrared (FTIR) spectroscopy, and by electrical measurements $(I-V, C-V)$ on MOS structures. A model of the growth mechanism for each of the processes is suggested. (C) 1999 Elsevier Science Ireland Ltd. All rights reserved.
\end{abstract}

Keywords: Atomic and molecular studies; Deposition process; Plasma processing and deposition; Silicon oxide

\section{Introduction}

$\mathrm{SiO}_{2}$ thin films are the most important dielectrics and passivation layers in large and ultra-large scale integration of micro- and nanoelectronic devices like non-volatile memories and LOGICs [1-3] or Josephson cache memories [4]. Low-temperature $\mathrm{SiO}_{x}$ are widely employed for their unique electrical, optical and mechanical properties. Substoichiometric oxides in intermetal dielectric stacks can improve the electronic properties of multilevel interconnection devices because they can better water molecules. The high number of dangling bonds in $\mathrm{Si}$ rich $\mathrm{SiO}_{x}$ enhances the chemical reactivity for oxides. Thus, water molecules can be subtracted from the surrounding layers [2]. Optoelectronic applications of $\mathrm{SiO}_{x}$ films include facet coatings of semiconductor lasers [5], resonant cavity photodetectors [6] and waveguides [7].

New photonic devices as well as electronic devices with a long-term reliability awakened a high interest in silicon nitrides and silicon oxynitrides for encapsulation and passi-

* Corresponding author. Tel.: + 49-8121-71227; fax: + 49-8121973763.

E-mail address: achim.strass@infineon.com (A. Strass) vation in packaging of integrated circuits, or as an insulating layer in metal-nitride-oxide-silicon (MNOS) devices [8]. Further applications include the use as gate dielectric in thin film transistors (TFT) [9], and as an antireflective protection layer in solar cells [10]. Nitrides are also attractive candidates for realizing smaller dimensions in ICs because of their high dielectric constant (7.0) compared to $\mathrm{SiO}_{2}$ (3.9) and because of their role as a diffusion layer against moisture and impurity ions. According to the SIA technology roadmap for semiconductors [11] low-leakage dielectrics with high permittivity will be required for DRAM storage node capacitors and on-chip filtering/decoupling.

For many purposes, high quality Si-based dielectrics are produced by high-temperature oxidation or nitridation between 700 and $1000^{\circ} \mathrm{C}$. Although, such insulators in general meet all requirements for modern devices, serious problems arise where thermal budget of the process is concerned. For example, MBE-grown nanostructure devices need sharp doping profiles or heterostructures on a nanometer scale for good electronic properties [12]. Process temperatures below $700^{\circ} \mathrm{C}$ are desirable to avoid dopant redistribution. To prevent interdiffusion of metallic layers like aluminum the process temperature must not exceed 


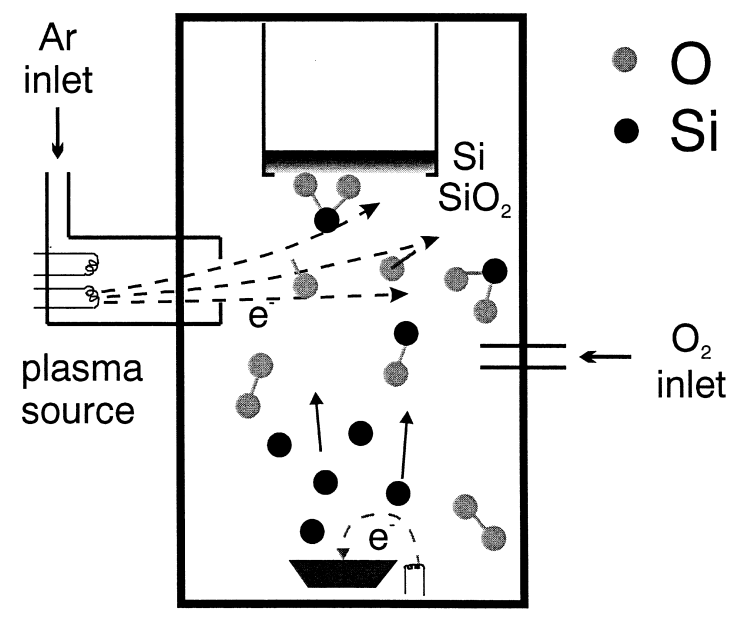

Fig. 1. Process chamber developed for plasma enhanced evaporation and similar processes.

$500^{\circ} \mathrm{C}$. Hence, very low substrate temperatures are desirable for the fabrication of such devices.

So far, $\mathrm{SiO}_{2}$ and substoichiometric silicon oxides have been fabricated by PECVD with silane and an oxidizing gas at temperatures below $450^{\circ} \mathrm{C}$ [13]. However, silane is a dangerous precursor and special care must be taken with the exhaust. One serious disadvantage is the high incorporation of hydrogen into the films coming from the $\mathrm{SiH}_{4}$ molecule. This leads to unwanted compounds like $\mathrm{Si}-\mathrm{H}$ or $\mathrm{Si}-$ $\mathrm{OH}$ which serve as charge traps. This has negative impacts on the dielectric characteristics. Another approach has been the evaporation of solid silicon monoxide $(\mathrm{SiO})$ targets in oxygen atmosphere [5]. Using this target material, however, does not allow the fabrication of $\mathrm{SiO}_{x}$ with $x<1$. Furthermore, it can be difficult to control the evaporation of $\mathrm{SiO}$ by electron beam heating because of its thermal decomposition and particle splitting.

Hence, novel low-temperature oxidation processes have been investigated recently. PEO (plasma enhanced oxidation) delivers oxides by burning a low-energy electron arc in oxygen atmosphere with the Si substrate merged into the plasma. It is eligible for the growth of very thin dielectric layers between 5 and $30 \mathrm{~nm}$. For PEE (plasma enhanced evaporation), $\mathrm{Si}$ is evaporated in addition to the plasma. We mainly use it for the fabrication of Si-based nitrides or oxynitrides with a thickness of 20-300 nm. GEE (gas enhanced evaporation) works like PEE only with the plasma switched off because, unlike nitrogen, oxygen naturally reacts with silicon. These techniques offer many advantages over conventional oxide fabrication methods such as accurate determination of the flux, low background contamination, in-situ process monitoring tools, safe operation and a wide process window. All processes can be performed at room temperature and are UHV- and MBE-compatible as they can be easily performed directly after MBE growth in the same chamber without interrupting the UHV conditions.

It is the objective of this paper to compare the electronic, optoelectronic and stoichiometric properties of the oxide films fabricated by the above mentioned low-temperature processes. Many characterisation methods were used to collect as much information on the films as possible because single techniques are all limited. Also, the experimental results are the basis for a discussion of the dynamics of film growth. Fields of applications are suggested.

\section{Experimental setup and film growth}

The UHV chamber is tested for multiple use such as MBE, oxide growth and hydrogen plasma cleaning of the substrates prior to any further process. The process chamber [14], is part of the Modular UHV multichamber system (MUM 545) from Balzers AG, Liechtenstein [15]. The base pressure in the chamber is typically $5 \times 10^{-9}$ mbar. All oxides were deposited on high-ohmic p-type (100) oriented silicon substrates. Generally, after a standard RCA cleaning the wafers were immediately introduced into the load-lock of the modular UHV multichamber system. Our standard hydrogen plasma cleaning was applied to remove the native oxide and organic contamination from the substrate surface at room temperature. The principle of the processes is illustrated in Fig. 1 and is described in the following paragraphs.

\subsection{Gas enhanced evaporation (GEE)}

For subsequent deposition of $\mathrm{SiO}_{x}$ layers silicon was evaporated from a crucible under $\mathrm{O}_{2}$ gas atmosphere. The deposited $\mathrm{Si}$ atoms naturally react with the $\mathrm{O}_{2}$ molecules at the surface. The deposition rate of Si under UHV conditions was determined by a quadrupole mass spectrometer (QMG) before oxygen was introduced. The gas pressure in the chamber was kept constant by mass flow controllers. Films were grown with oxygen flows ranging from 0.8 sccm $\left(1.5 \times 10^{-3} \mathrm{~Pa}\right)$ to $73 \mathrm{sccm}(0.1 \mathrm{~Pa})$ at a substrate temperature of $360^{\circ} \mathrm{C}$ for most of the samples. The evaporation rate of $\mathrm{Si}$ in the UHV was kept constant at $0.3 \AA / \mathrm{s}$. The growth rate of $\mathrm{SiO}_{x}$ depends on the reduced mean free path of the evaporated molecular beam at high gas pressures and on the growth kinetics at the substrate surface. The mean free path falls below $45 \mathrm{~cm}$, which is the distance between the substrate and the Si target, at an oxygen pressure of greater than approximately $4 \times 10^{-2} \mathrm{~Pa}$. One sample was grown in pure $\mathrm{N}_{2}$ gas atmosphere at a substrate temperature of $360^{\circ} \mathrm{C}$.

\subsection{Plasma enhanced evaporation (PEE)}

Gases like $\mathrm{N}_{2}$ which do not naturally react with silicon are cracked by a low-energy plasma to form $\mathrm{Si}_{3} \mathrm{~N}_{4}$ or together with $\mathrm{O}_{2}$ oxynitride insulators [14], but for a better point of view the principle is summarized briefly. A low-energy electron arc of high volume is created by a DC discharge from the negative-biased filament to the grounded chamber walls (anode). The substrate, merged into the plasma, is also 
grounded. The average kinetic energy of the electrons is estimated to be $5-10 \mathrm{eV}$ which is enough to dissociate but not ionize the process gas [16]. Thereby, substrate damage is avoided. In addition to $\mathrm{O}_{2}$, a minimum amount of $20 \mathrm{sccm}$ $\operatorname{Ar}\left(6 \times 10^{-2} \mathrm{~Pa}\right)$ is needed as a working gas to create the plasma. Thus, the total process pressure is typically higher than $8 \times 10^{-2} \mathrm{~Pa}$. This low Ar flow was used for all PEE processes to keep the mean free path in the gas as large as possible. Numerous $\mathrm{SiO}_{x}$ and $\mathrm{SiO}_{x} \mathrm{~N}_{y}$ films were grown with different $\mathrm{Si}$ evaporation rates at room temperature and at $360^{\circ} \mathrm{C}$. The oxygen gas flow was varied between $1.5 \mathrm{sccm}$ $\left(2.3 \times 10^{-3} \mathrm{~Pa}\right)$ and $15 \mathrm{sccm}\left(2.6 \times 10^{-2} \mathrm{~Pa}\right)$. Oxynitrides were grown with an $\mathrm{O}_{2} / \mathrm{N}_{2}$ flow of $0 / 8,2 / 6$ and $4 / 4 \mathrm{sccm}$ at $360^{\circ} \mathrm{C}$.

\subsection{Plasma enhanced oxidation (PEO)}

A third method of growing $\mathrm{SiO}_{2}$ is by plasma enhanced oxidation (PEO). It works like PEE only with the evaporator switched off. The Ar flow was maintained at $80 \mathrm{sccm}$ $\left(1.2 \times 10^{-1} \mathrm{~Pa}\right)$ for most of the samples because under this condition the plasma was found to be very stable and of good geometry. The oxygen flow was fixed at $10 \mathrm{sccm}$. The process pressure was typically $0.5 \mathrm{~Pa}$. Plasma oxynitrides were grown with an $\mathrm{O}_{2} / \mathrm{N}_{2}$ flow of $0 / 10 \mathrm{sccm}$ (room temperature and $\left.360^{\circ} \mathrm{C}\right)$ and $5 / 5 \mathrm{sccm}\left(360^{\circ} \mathrm{C}\right)$.

\section{Film characterisation methods}

The thickness and the refractive index of the as-deposited oxide layers were determined at fixed wavelength $(633 \mathrm{~nm})$ and fixed incident angle $\left(70^{\circ}\right)$ with a PLASMOS SD 2300 ellipsometer. The measurements were carried out systematically in $\mathrm{N}$-float and $\mathrm{N}$-fix modus at several points for each sample. The validity of the thickness measurements was confirmed by comparison with the results obtained from a mechanical profilometer (Sloan Dektak II).

For electrical characterization, Al pads were evaporated on the films through a mechanical shadow mask to form metal-insulator-semiconductor (MIS) diodes with an area of $7.8 \times 10^{-3} \mathrm{~cm}^{2}$. The electrical back side contact to the metal chuck was ensured by conducting silver. We avoided sputtering the back side because in our experiments it sometimes caused electrical damage to very thin dielectric films. Capacitance-voltage $(C-V)$ and conductance-voltage $(G-V)$ measurements were obtained from a HP4275 multi frequency LRZ meter. A Keithley-230 programmable voltage source as well as a Keithley-617 programmable electrometer were used for dynamic ramp current-voltage $(I-V)$ measurements. The current was measured $3 \mathrm{~s}$ after the applied voltage was increased in steps of $0.3 \mathrm{~V}$.

Electrical and optical properties of dielectrics are very sensitive to stoichiometry and impurities. Thus, we characterized the stoichiometry and impurity level by electron spectroscopy (AES and XPS), as well as by RBS and FTIR.

Prior to surface electron spectroscopy the samples have to be sputter-cleaned for two reasons. The surface is usually covered with adsorbed carbon, hydrocarbons or carbon oxides leading to a weaker signal of the $\mathrm{SiO}_{x}$ compound and to errors in the determination of the atomic concentration of the elements. Furthermore, when exposed to air, native $\mathrm{SiO}_{2}$ is formed on $\mathrm{SiO}_{x}$ surfaces with $x<2$. To reduce damage, the samples were first sputtered by ions of higher kinetic energy and subsequently by a beam of lower energy.

Auger electron spectroscopy (AES) enables the determination of relative atomic concentrations and - to a certain extent - chemical analysis of a film. AES measurements were performed on a Perkin-Elmer ESCA/Auger system, PHI model ESCA 550, with a double pass cylindrical mirror analyzer. The base pressure in the analysis chamber was typically $1.0 \times 10^{-7} \mathrm{~Pa}$. The samples were all sputtercleaned prior to analysis by an $\mathrm{Ar}^{+}$ion beam of $3 \mathrm{kV}$ for $60 \mathrm{~s}$ and $1 \mathrm{kV}$ for another $60 \mathrm{~s}$ from a differentially pumped Perkin-Elmer, PHI model 04-303 ion gun. Next to rough surveys, high resolution spectra were recorded with a kinetic energy of $3 \mathrm{kV}$ of the incident electron beam for Si LVV and O KLL and of $5 \mathrm{kV}$ for Si KLL. These energies were used to obtain strong signals for Si LVV and Si KLL, respectively. The current through the sample was fixed to $300 \mathrm{nA}$ in each case. It should be noted that a quantitative analysis of the atomic concentration of $\mathrm{Si}$ and $\mathrm{O}$ is hardly possible in substoichiometric $\mathrm{SiO}_{x}$. The peak for Si LVV splits for substoichiometric $\mathrm{SiO}_{x}$ with maxima at $76 \mathrm{eV}$ (for $\mathrm{SiO}_{2}$ ) and $92 \mathrm{eV}$ (for elemental $\mathrm{Si}$ ) in the differentiated surface spectrum [17].

$\mathrm{X}$-ray photoelectron spectroscopy, also known as electron spectroscopy for chemical analysis (ESCA) was used to determine the chemical state of the oxides as well as the atomic concentrations of the elements. For XPS measurements a Perkin-Elmer, PHI model 1257, ESCA spectrometer with a concentric hemispherical electron analyzer was used with a pass energy of $20 \mathrm{eV}$. The pressure in the analysis chamber was typically $2 \times 10^{-8} \mathrm{~Pa}$. Photoelectrons were excited by $\mathrm{Mg} \mathrm{K}_{\alpha} \mathrm{X}$-rays with $h \nu=1253.6 \mathrm{eV}$. The binding energy scale was calibrated with the $\mathrm{C}$ 1s photoelectron line at $284.6 \mathrm{eV}$ to correct the charging effect. All experiments were performed at a takeoff angle of $54^{\circ}$, (the so called magic XPS angle) with respect to the surface plane. For $\mathrm{Ar}^{+}$sputtering a Perkin-Elmer, PHI model 04303 ion gun was applied. The samples were first bombarded by $2 \mathrm{keV}$ ions ( $5 \mathrm{mC}$ charge in total) and subsequently by 1 $\mathrm{keV}$ ions $(2 \mathrm{mC})$ for a mild treatment. The sputtered area was about $0.5 \mathrm{~cm}^{2}$.

Rutherford Backscattering (RBS) measurements were done to find out the atomic composition of the films. Analyses were done on a High Voltage Engineering Europe B.V. accelerator and end station. The incident beam consisted of $1 \mathrm{MeV} 4-\mathrm{He}^{+}$ions and was directed perpendicular to the sample surface. RBS data were collected at a backscatter angle of $75^{\circ}$. Since the information is obtained 
Table 1

Typical values for film thickness, growth rate and refractive index of $\mathrm{SiO}_{2}$ fabricated by three different growth methods. The values given for the refractive index of PEE-grown $\mathrm{SiO}_{2}$ is only valid for films thicker than $150 \AA$

\begin{tabular}{|c|c|c|c|}
\hline & $\begin{array}{l}\text { Gas } \\
\text { enhanced } \\
\text { evaporation } \\
\text { (GEE) }\end{array}$ & $\begin{array}{l}\text { Plasma } \\
\text { enhanced } \\
\text { evaporation } \\
\text { (PEE) }\end{array}$ & $\begin{array}{l}\text { Plasma } \\
\text { enhanced } \\
\text { oxidation } \\
(\mathrm{PEO})\end{array}$ \\
\hline Layer thickness $(\AA)$ & $400-600$ & $200-2000$ & $40-300$ \\
\hline Lateral uniformity (\%) & $<3$ & $2-6$ & $2-6$ \\
\hline Growth rate $(\AA / s)$ & $0.25-0.80$ & $0.2-3$ & $0.03-0.2$ \\
\hline Refractive index & $1.42-1.48$ & $1.45-1.49$ & $1.44-1.47$ \\
\hline Lateral uniformity (\%) & $<1$ & $<2$ & $0.5-2$ \\
\hline
\end{tabular}

from nuclei scattering, no chemical data are available by this method.

Fourier transformed transmission infrared (FTIR) absorption spectra were taken from $\mathrm{SiO}_{x}$ samples to study the bonding configuration in the bulk of the films. The location of the absorption band identifies the chemical bond, the concentration of the bond determines the intensity of the peak. A Nicolet 5PC FTIR spectrometer operating in the mid-infrared region $\left(400-4000 \mathrm{~cm}^{-1}\right)$ was used to obtain the data. The recorded data are corrected by a fitted baseline (to account for interference effects in the film) and subtracting the spectra of a bare silicon substrate to eliminate the silicon peaks.

Three samples were used as a reference for the performed measurements: elemental $\mathrm{Si}$, wet thermal $\mathrm{SiO}_{2}$, and CVD$\mathrm{Si}_{3} \mathrm{~N}_{4}$.

\section{Experimental results}

In this section the experimental results are presented and - if possible - compared for the three low-temperature oxide fabrication processes. The measured film properties and the experiments on dynamics of film growth are the basis for the discussion in the following section.

Table 1 gives an overview over typical values for refrac-

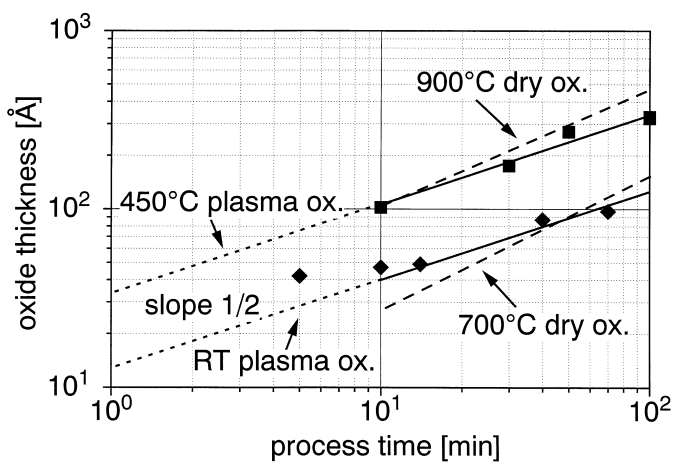

Fig. 2. Double-logarithmic plot of the PEO oxide thickness versus duration to $\mathrm{O}_{2}$ plasma exposure. The dashed lines for dry oxidation are shown for comparison [19].

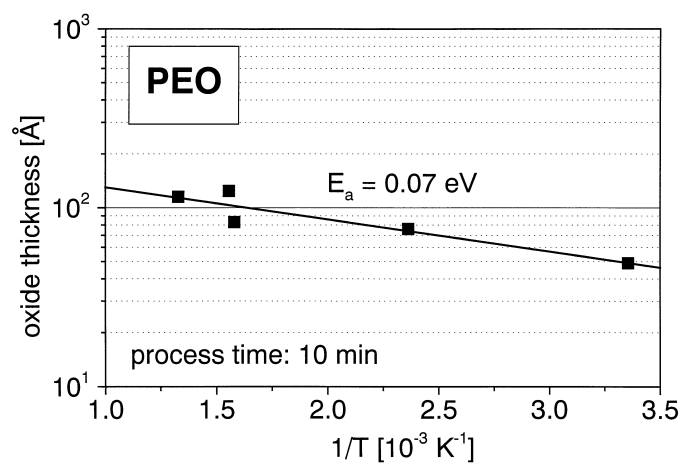

Fig. 3. Arrhenius plot of PEO oxide thickness as a function of inverse temperature.

tive index, film thickness and growth rate for all three processes. The very low growth rates for PEO clearly show that pure plasma oxide growth is not a competitive process to PEE where film growth is accelerated by evaporation. Because of the similarity of both growth methods, the typical lateral uniformity in thickness for the GEEsamples corresponds to that of pure Si MBE deposition of Si in the UHV. The PEE and PEO samples show a higher thickness at locations closer to the plasma source. This could be improved by a sweeping arc and by substrate rotation or by a different chamber geometry. The lateral uniformity in the refractive index is below $2 \%$ for all samples.

Fig. 2 shows a double logarithmic plot of the PEO oxide thickness versus the duration of exposure to the oxygen plasma. Above $10 \mathrm{~min}$ the thickness of the grown $\mathrm{SiO}_{2}$ layers is directly proportional to the square root of the process time. This time dependence is conferred from the slope $(1 / 2)$ of the plot indicating that the oxidation kinetics is limited by the diffusion of oxidizing species through the growing film rather than by the flux of species to the surface. Hence, for a thickness of more than $50 \AA$ the growth is obviously transport rate limited and thus comparable to thermal oxidation where the relatively large oxygen molecules diffuse through the oxide layer, followed by the reaction at the $\mathrm{Si} / \mathrm{SiO}_{2}$ interface, first described by Deal and Grove [18]. Films grown in a pure $\mathrm{N}_{2}$ plasma are only half as thick as those grown in a pure $\mathrm{O}_{2}$ plasma under the same or similar conditions.

Compared to thermal oxidation, film growth by PEO proceeds much more rapidly leading to the conclusion that the plasma supplies particles that diffuse easier as compared to $\mathrm{O}_{2}$ molecules. With our conditions, plasma oxidation rates at room temperature and $450^{\circ} \mathrm{C}$ are nearly the same as compared with those found in standard literature for dry thermal oxidation at 700 and $900^{\circ} \mathrm{C}$, respectively [19]. The slope for thermal oxides is actually a bit higher than $1 / 2$ because the Deal-Grove model is valid for thicknesses above $300 \AA$. Furthermore, the $\mathrm{SiO}_{2}$ growth rates show Arrhenius dependence versus substrate temperature with a positive activation energy of $0.07 \mathrm{eV}$ (Fig. 3). This value is nearly three times smaller than the value of $0.19 \mathrm{eV}$ found 


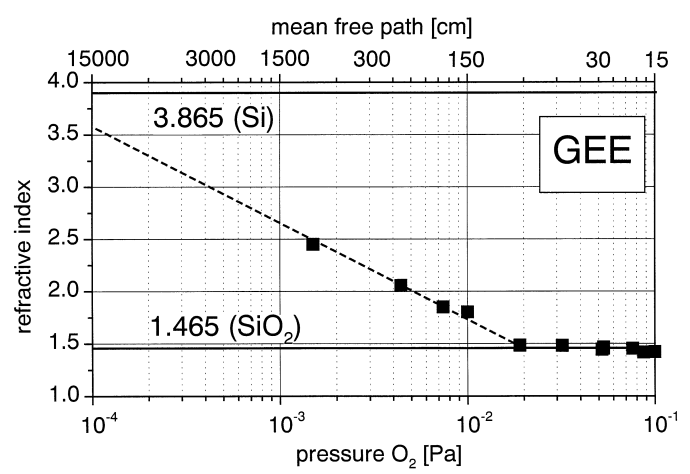

Fig. 4. Refractive index of GEE-grown $\mathrm{SiO}_{x}$ as a function of $\mathrm{O}_{2}$ pressure during Si evaporation.

by $\mathrm{Hu}$ et al, in a similar experiment [20]. The activation energy is significantly smaller than for dry thermal oxidation where it amounts to $2.22 \mathrm{eV}$ [18].

The refractive index of the GEE-grown samples, measured by ellipsometry, can be easily set by varying the $\mathrm{O}_{2}$ flow into the chamber as shown in Fig. 4. Above $2 \times$ $10^{-2} \mathrm{~Pa}$ the mean free path of the Si atoms is lower than the distance between the crucible with the $\mathrm{Si}$ target and the substrate which is $45 \mathrm{~cm}$. The refractive index indicates that stoichiometric $\mathrm{SiO}_{2}$ is formed under these conditions. Below $2 \times 10^{-2} \mathrm{~Pa}$ the refractive index of the deposited layer exponentially grows with decreasing $\mathrm{O}_{2}$ pressure in the chamber. By extrapolation, the refractive index of crystalline Si (3.8) should be reached at an approximate oxygen pressure of $5 \times 10^{-5} \mathrm{~Pa}$. It should be mentioned that the accuracy of ellipsometric measurements decreases for very $\mathrm{Si}$ rich oxides because of lower transparency at the wavelength of $633 \mathrm{~nm}$.

\subsection{Auger electron spectroscopy (AES)}

All oxide films as loaded into the AES analysis chamber only show surface contamination by $\mathrm{C}$. After the sputter cleaning the concentration of $\mathrm{C}$ fell below the detection limit of $1 \%$. Fig. 5 displays changes in $\mathrm{Si} \mathrm{LVV}$ and $\mathrm{Si}$ KLL as a function of the refractive index $n$ for a selection of GEE oxides. These results are compared with measurements obtained from thermal $\mathrm{SiO}_{2}$ and pure $\mathrm{Si}$. The $\mathrm{Si} \mathrm{LVV}$ peak at $92 \mathrm{eV}$ increases at the expense of the peak at $76 \mathrm{eV}$ for increasing Si:O ratio $x$. The Si KLL peak moves from $1622.5 \mathrm{eV}$ for $x=2$ to $1612.5 \mathrm{eV}$ for $x=0$. The position of the $\mathrm{O}$ KLL is located around $505 \mathrm{eV}$ for all samples (not shown here). Slight deviations to the literature values [17] are due to charging effects. The AES peak locations show the presence of $\mathrm{Si}, \mathrm{SiO}_{2}$ and $\mathrm{SiO}_{x}$ phases in substoichiometric silicon oxide films (samples GEE6, GEE5, GEE4 from Table 2). The Si LVV peak of the near stoichiometric GEE specimen (GEE3, GEE1, GEE2) is not as sharp as that of the thermal $\mathrm{SiO}_{2}$. This indicates that slight amounts of silicon-rich clusters are incorporated into the films by the evaporation process or that the layers are not as dense as
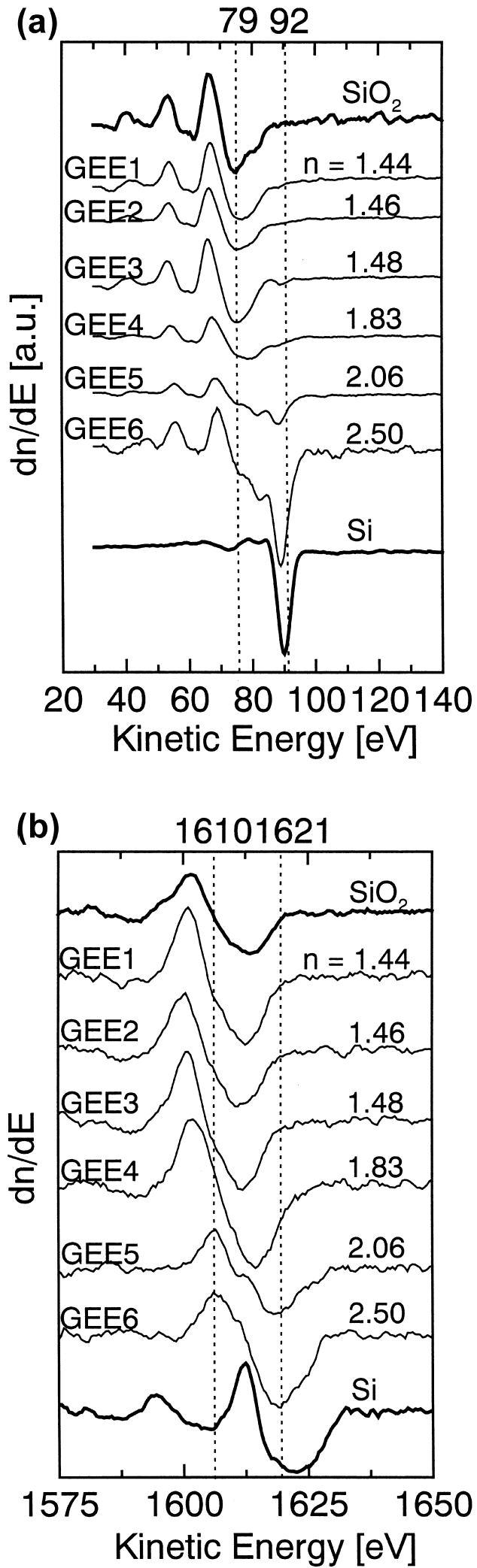

Fig. 5. Changes of the (a) Si KLL and (b) Si LVV Auger spectra of GEE oxides as a function of refractive index. The curves of thermal $\mathrm{SiO}_{2}$ and of elemental $\mathrm{Si}$ are shown for comparison. The dashed lines give the literature values of the bottom peak of $\mathrm{Si} \mathrm{LVV} \mathrm{(76} \mathrm{eV} \mathrm{for} \mathrm{SiO}_{2}, 92 \mathrm{eV}$ for $\mathrm{Si}$ ) and $\mathrm{Si}$ KLL (approximately $1610 \mathrm{eV}$ for $\mathrm{SiO}_{2}, 1621 \mathrm{eV}$ for $\mathrm{Si}$ ) [17]. 
Table 2

Comparison of two GEE- and PEE-deposited films with respect to refractive index and stoichiometry. The thicknesses values in parentheses are measured by mechanical profilometry. Ellipsometer measurements were not possible due to high absorption at $632 \mathrm{~nm}$ wavelength

\begin{tabular}{|c|c|c|c|c|c|c|c|c|}
\hline WAFER & $\begin{array}{l}\mathrm{O}_{2} \text { partial } \\
\text { pressure } \\
(\mathrm{mbar})\end{array}$ & $\begin{array}{l}\text { Gas } \\
\text { flow } \\
(\mathrm{sccm}) \\
\mathrm{O}_{2}\end{array}$ & $\begin{array}{l}\text { Gas } \\
\text { flow } \\
\text { (sccm) } \\
\mathrm{N}_{2}\end{array}$ & $\begin{array}{l}\text { Refractive } \\
\text { index }\end{array}$ & $\begin{array}{l}\text { Ratio Si:O } \\
(\%)(\mathrm{RBS})\end{array}$ & $\begin{array}{l}\text { Ratio Si:O:N } \\
(\%) \text { (XPS) }\end{array}$ & $\begin{array}{l}\text { Ratio x O:Si } \\
\text { x (XPS) }\end{array}$ & $\begin{array}{l}\text { Thickness } \\
\text { (ellipsom) } \\
(\AA)\end{array}$ \\
\hline GEE1 & $5.4 \times 10^{-4}$ & 30 & - & 1.44 & $31: 69$ & $33: 67$ & 2 & 680 \\
\hline GEE2 & $5.2 \times 10^{-4}$ & 30 & - & 1.47 & $33: 67$ & $33: 67$ & 2 & 454 \\
\hline GEE3 & $1.9 \times 10^{-4}$ & 10 & - & 1.48 & - & $33: 67$ & 2 & 567 \\
\hline GEE4 & $1.0 \times 10^{-4}$ & 7 & - & 1.83 & - & $36: 64$ & 1.75 & 547 \\
\hline GEE5 & $4.4 \times 10^{-5}$ & 2.3 & - & 2.06 & $40: 60$ & $42: 58$ & 1.38 & 520 \\
\hline GEE6 & $1.5 \times 10^{-5}$ & 0.8 & - & 2.50 & $48: 52$ & $52: 48$ & 0.92 & 460 \\
\hline PEE1 & $1.4 \times 10^{-4}$ & 10 & - & 1.466 & - & $33: 67$ & 2 & 1704 \\
\hline PEE2 & $1.4 \times 10^{-4}$ & 10 & - & 1.474 & - & $33: 67$ & 2 & 1489 \\
\hline PEE3 & $2.4 \times 10^{-5}$ & 1.5 & - & - & - & $71: 29$ & 0.41 & 1050 \\
\hline PEE4 & $2.1 \times 10^{-5}$ & 1.5 & - & - & - & $76: 24$ & 0.32 & 1043 \\
\hline PEE5 & - & 0 & 8 & 1.91 & - & $35: 16: 49$ & - & 371 \\
\hline PEE6 & $2.7 \times 10^{-5}$ & 2 & 6 & 1.51 & - & $25: 73: 3$ & - & 334 \\
\hline PEE7 & $7.0 \times 10^{-5}$ & 4 & 4 & 1.57 & - & $36: 64: 0$ & - & 282 \\
\hline
\end{tabular}

thermal $\mathrm{SiO}_{2}$, which may cause changes in the angle of the $\mathrm{SiO}_{2}$ molecule. When the $\mathrm{Si}$ and $\mathrm{O}$ atomic concentrations are nearly equal (sample GEE6), the film consists of a mixture of all $\mathrm{SiO}_{x}$ phases $(x=0,1,1.5,2)$ as indicated by the broad peak. This will be confirmed by XPS data as shown below. No incorporated nitrogen was found neither by AES nor by XPS in the deposited Si layer of the GEE sample grown in $\mathrm{N}_{2}$ gas atmosphere.

AES spectra were also taken for PEE grown samples with different $\mathrm{N}_{2}: \mathrm{O}_{2}$ gas mixtures in the plasma in order to grow oxynitrides. No $\mathrm{N}$ was found for PEE7, where the $\mathrm{N}_{2}: \mathrm{O}_{2}$ flow ratio was lowest (compared to PEE5 and PEE6), neither by AES nor by XPS. The atomic concentration of $\mathrm{N}$ for PEE6 was determined to $7 \%$. The depth profile as well as a surface spectrum of sample PEE5 after 3 min sputtering, which was deposited by PEE in the nitrogen plasma, is shown in Fig. 6. After correction for relative sensitivities, the film is composed of $35 \% \mathrm{Si}, 49 \% \mathrm{~N}$ and $16 \% \mathrm{O}$. The relatively high incorporation of $\mathrm{O}$ is attributed to the deso-

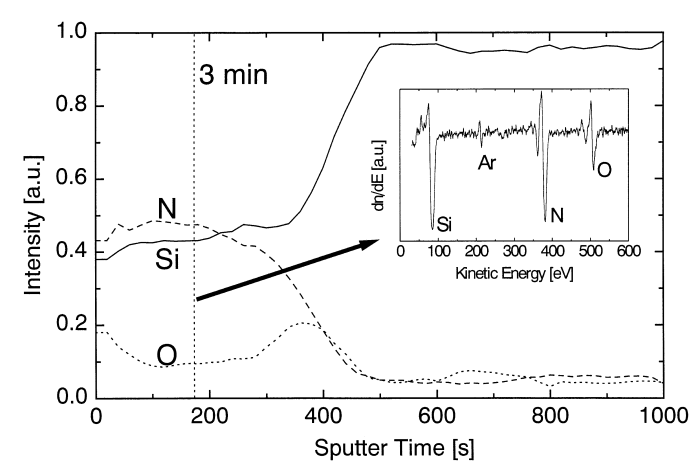

Fig. 6. AES depth profile of SiON sample PEE5. The surface spectrum after a part of the bulk layer was removed verifies the atomic concentrations. rption of residual oxygen from the process chamber by plasma radicals. The high $\mathrm{Si}$ content indicates that, even though activated by the plasma, nitrogen is very reluctant to react with the deposited $\mathrm{Si}$ species. A fairly vertical uniform distribution is followed by a rather abrupt transition region. In this region, the Si content increases concurrently with the decreasing nitrogen content while the $\mathrm{O}$ profile faces a slight maximum at the interface. This is also due to residual oxygen which reacts much easier with the dangling bonds of the Si surface than nitrogen at the beginning of film growth. Even a CVD- $\mathrm{Si}_{3} \mathrm{~N}_{4}$ sample contains $7 \%$ oxygen. Fig. 7 summarizes the spectra of Si LVV and $\mathrm{Si}$ KLL of the PEE samples PEE5, PEE6 and PEE7. The curves for $\mathrm{Si}$, thermal $\mathrm{SiO}_{2}, \mathrm{CVD}-\mathrm{Si}_{3} \mathrm{~N}_{4}$ and PEO (plasma enhanced oxidation) oxide are shown for reference. With growing concentration of incorporated oxygen in the PEESiON samples the Si KLL peak shifts as expected from 76 to $84 \mathrm{eV}$, the literature values for $\mathrm{SiO}_{2}$ and $\mathrm{Si}_{3} \mathrm{~N}_{4}$ [17]. All stoichiometric and substoichiometric oxides grown by any method were found to be uniform by AES in depth distribution.

It was further found by AES that more $\mathrm{O}$ than $\mathrm{N}$ species were incorporated into the thin PEO films grown in pure $\mathrm{N}_{2}$ plasma. No nitrogen was detectable in the film grown in an $\mathrm{N}_{2} / \mathrm{O}_{2}$ plasma with $5 \mathrm{sccm}$ of each gas. The bulk mainly consists of $\mathrm{SiO}_{2}$.

\subsection{X-ray photoelectron spectroscopy (XPS)}

The XPS survey spectra of all substoichiometric oxides before sputtering show a small amount of adventitious C and native oxide, of which both were removed by sputtering. This is demonstrated in Fig. 8 with the sample GEE5. After sputtering, the $\mathrm{Si} 2 \mathrm{p}$ as well as the $\mathrm{O} 1$ s peaks are slightly broadened, even for the thermal $\mathrm{SiO}_{2}$ and the CVD- 

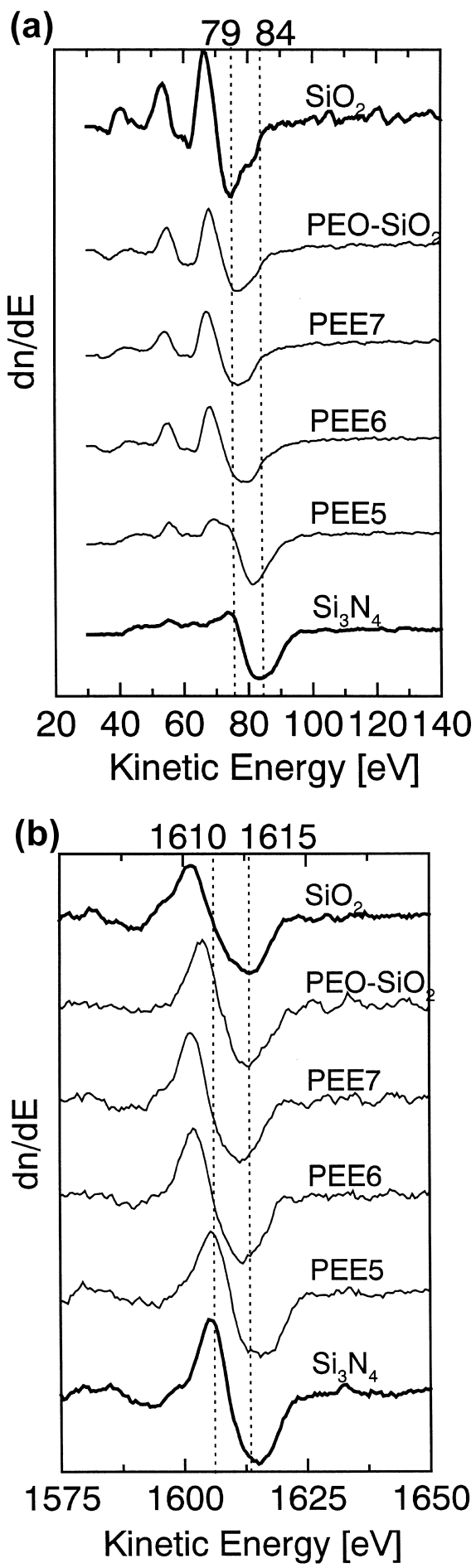

Fig. 7. Changes of the (a) Si LVV and (b) Si KLL Auger spectra of PEE $\mathrm{SiON}$ films as a function of refractive index. The curves of PEO-SiO thermal $\mathrm{SiO}_{2}$ and of elemental $\mathrm{Si}$ are shown for comparison. The dashed lines give the literature values of the bottom peak of Si LVV (76 eV for $\mathrm{SiO}_{2}, 84 \mathrm{eV}$ for $\mathrm{Si}_{3} \mathrm{~N}_{4}$ ) and $\mathrm{Si} \mathrm{KLL}$ (approximately $1610 \mathrm{eV}$ for $\mathrm{SiO}_{2}, 1615$ $\mathrm{eV}$ for $\mathrm{Si}_{3} \mathrm{~N}_{4}$ ) [17]. The $\mathrm{O}_{2}: \mathrm{N}_{2}$ gas mixture was $4: 4,2: 6$ and $0: 8 \mathrm{sccm}$ for the samples PEE7, PEE6, and PEE5, respectively.

$\mathrm{Si}_{3} \mathrm{~N}_{4}$ specimen. This can be attributed to slight lattice damage caused by ion bombardment. Fig. 9 shows the high resolution $\mathrm{Si} 2 \mathrm{p}$ spectra of GEE grown oxides

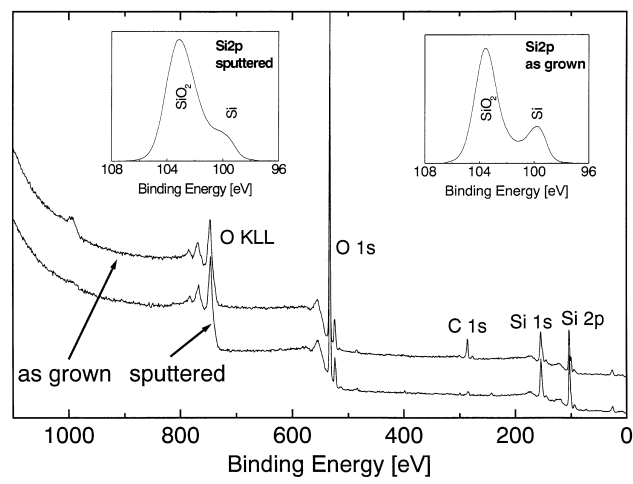

Fig. 8. Survey spectrum of $\mathrm{SiO}_{x}$ sample GEE5 before and after sputtercleaning.

compared with those of thermal $\mathrm{SiO}_{2}$ and the $\mathrm{Si}$ substrate with the peak positions close to the literature values of 103.3 and $99.3 \mathrm{eV}$, respectively [21]. As already demonstrated by the AES spectra, the peak of the $\mathrm{SiO}_{x}$ films is broadened or even split depending on the composition. This indicates the presence of more than one oxidation state.

The quantity of $\mathrm{Si}$ in the films was determined from the XPS spectra as follows. The background was subtracted from the Si $2 p$ peak. Five symmetric Gaussian bands representing the different valence states $\mathrm{Si}, \mathrm{Si}^{+}, \mathrm{Si}^{2+}, \mathrm{Si}^{3+}$ and $\mathrm{Si}^{4+}$ were added with the maximum at binding energies of $99.4,100.3,101.3,102.2$, and $103.4 \mathrm{eV}$ with a tolerance of $\pm 0.2 \mathrm{eV}$. The FWHM was fixed to $1.4 \pm 0.2 \mathrm{eV}$ for all states except for the $\mathrm{Si}^{4+}$ subband where $1.7 \pm 0.2 \mathrm{eV}$ was used. The peak positions and the FWHM values are in good agreement with those in the literature [22,23]. Elemental Si and $\mathrm{Si}-\mathrm{H}$ differ by only $0.35 \mathrm{eV}$ and were thus fitted as a single peak [24]. The average atomic concentration ratio $x=\mathrm{O}: \mathrm{Si}$ was calculated by the $\mathrm{Si} 2 \mathrm{p}$ subbands as follows [23]

$x=\frac{1}{2}\left(\sum_{n=1}^{4} n A\left(\mathrm{Si}^{n+}\right) / \sum_{n=0}^{4} A\left(\mathrm{Si}^{n+}\right)\right)$

Here, $A\left(\mathrm{Si}^{n+}\right)$ represents the relative amount of the $\mathrm{Si}$ valence states from the curve fits, which were determined

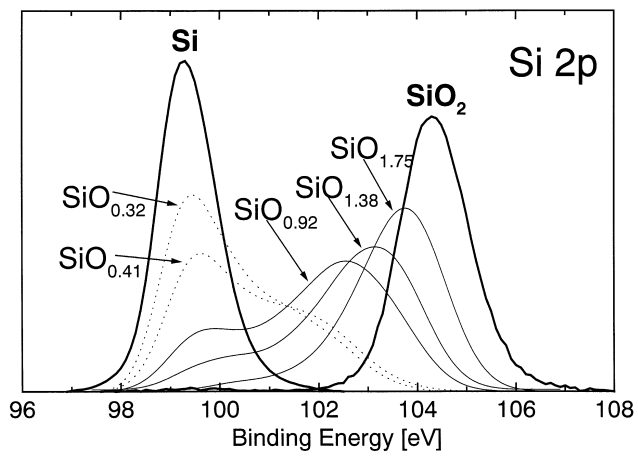

Fig. 9. Si $2 p$ spectra measured by XPS of silicon suboxides grown by GEE (straight line) and PEE (dashed line). The curves of thermal $\mathrm{SiO}_{2}$ and of elemental $\mathrm{Si}$ are shown for comparison. 


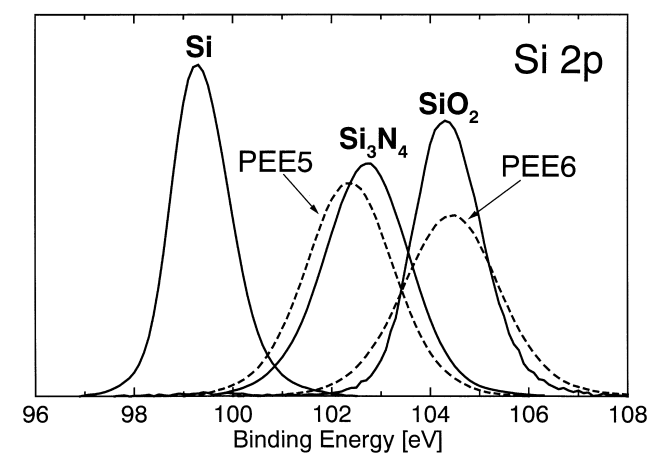

Fig. 10. Si 2p spectra measured by XPS of silicon oxynitrides grown by PEE. The curves of thermal $\mathrm{SiO}_{2}, \mathrm{CVD}-\mathrm{Si}_{3} \mathrm{~N}_{4}$ and of elemental $\mathrm{Si}$ are shown for comparison.

by calculating the area under each subpeaks. For the silicon oxynitride samples this method is difficult because there are too many valence states possible. Thus the conventional method of comparing different peak areas normalized by relative sensitivity factors given in [21] was used to roughly estimate the element concentrations.

Fig. 10 shows the Si 2p spectra of some oxynitrides. The peak position of PEE5 nearly equals that of CVD-Si $\mathrm{N}_{4}$. The slight shift to smaller binding energies is attributed to a surplus of Si. The Si 2p spectrum of PEE6 is not shifted from that of thermal $\mathrm{SiO}_{2}$ because the film only contains about 3\% nitrogen. The large FWHM indicates the presence of other phases than $\mathrm{SiO}_{2}$ in the film.

RBS spectra were taken from some GEE samples. The elemental concentrations determined by this method compare well with the XPS results as can be seen in Table 2. The thickness obtained by RBS is about $10-20 \%$ higher than the ellipsometer values. Thus, the deposited films are less dense than thermal oxides. This fits well with the earlier discussion of the AES results.

Regarding film composition, the AES and XPS results lead to the conclusion that silicon oxides of different stoichiometries can be fabricated by GEE depending on process parameters. For the plasma-assisted processes PEE and PEO, oxynitrides can be formed in addition. Since no

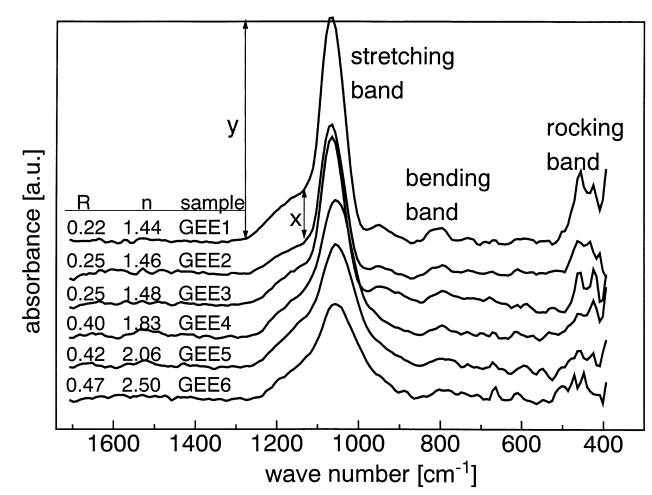

Fig. 11. Infrared absorption spectra of as-deposited $\mathrm{SiO}_{x}$ films grown by GEE.

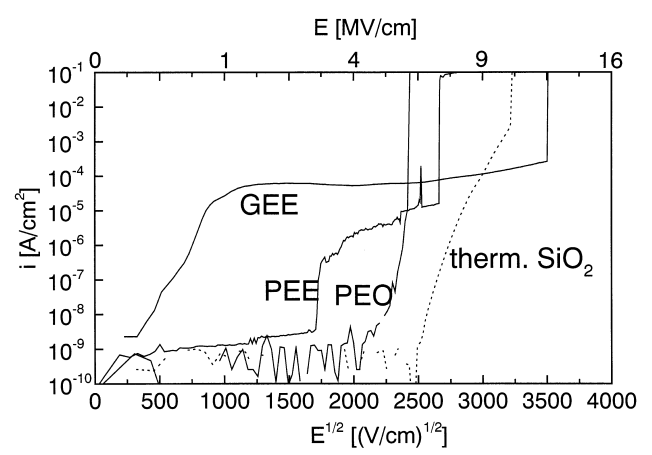

Fig. 12. Comparison of $I-V$ characteristics of different low-temperature oxides in MOS structures. The curve of thermal $\mathrm{SiO}_{2}$ is shown for reference.

evaporated silicon is offered during substrate oxidation, only $\mathrm{SiO}_{2}$ and no sub-oxides were formed by PEO.

\subsection{Infrared spectroscopy (IR)}

The IR spectra in the region of $400-1600 \mathrm{~cm}^{-1}$ in Fig. 11 show the $\mathrm{Si}-\mathrm{O}$ stretching, bending and rocking band of GEE-grown $\mathrm{SiO}_{x}$. The shoulder height of the main $\mathrm{Si}-\mathrm{O}$ stretching bend divided by the peak height $y$ is defined as the ratio $R$, thus $R=x / y$ [25]. $R$ is a function of film composition ranging from 0.22 for $\mathrm{SiO}_{2}$ to 0.47 for $\mathrm{Si}$ rich $\mathrm{SiO}_{0.92}$ $(n=2.50)$. Compared with the XPS results, samples with $n$ close to 1.46 have their stretching peak all at $1066 \mathrm{~cm}^{-1}$. For samples with $n$ greater than 1.48 (see Table 2) the $\mathrm{Si}-\mathrm{O}$ stretching frequency shifts towards lower wave numbers below $1057 \mathrm{~cm}^{-1}$. The spectra of the stoichiometric samples exhibit an extra absorption band in the region of 900-980 $\mathrm{cm}^{-1}$ between the bending and the stretching band. This extra peak merges with the broadened stretching band of the $\mathrm{Si}$ rich samples and is probably associated with the $\mathrm{Si}-\mathrm{H}$ bending mode in $\mathrm{H}_{2} \mathrm{SiO}_{2}$ groups [26]. The GEE films are too thin to clearly detect any $\mathrm{Si}-\mathrm{H}$ or $\mathrm{Si}-\mathrm{OH}$ absorption bands. Due to the limits of this method, it can only be concluded that the films contain $\mathrm{Si}-\mathrm{O}$ compounds. The changes of the shoulder heights agree with the results on stoichiometry obtained from XPS.

\subsection{Electrical characterization}

The relation between the leakage current and the electric field of one typical representative of the PEE-, GEE- and PEO-grown stoichiometric oxides is plotted in Fig. 12. The curve of a wet thermally grown oxide is shown for reference. The PEO sample exhibits no current injection until 4 $\mathrm{MV} / \mathrm{cm}$. The displacement current due to the voltage ramp is below $1 \times 10^{-9} \mathrm{~A} / \mathrm{cm}^{2}$. Some Fowler-Nordheim tunneling seems to occur before breakdown below $6 \mathrm{MV} / \mathrm{cm}$. There is no current injection due to charge trapping. A different behaviour is shown by the PEE sample. Below 3 $\mathrm{MV} / \mathrm{cm}$ a tiny displacement current of the order of $10^{-9} \mathrm{~A} /$ $\mathrm{cm}^{2}$ is present. Above $3 \mathrm{MV} / \mathrm{cm}$ electrons are injected, filling deep traps in the bulk of the oxide. This results in a ledge 


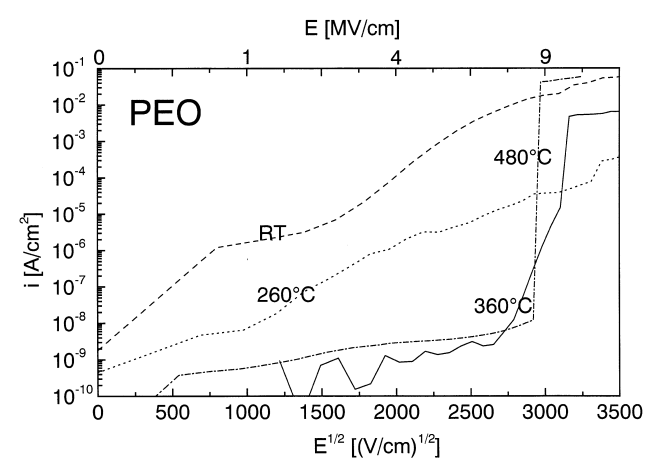

Fig. 13. Comparison of $I-V$ characteristics of PEO oxides in MOS structures grown at different substrate temperatures.

of the logarithmic $I-V$ plot for the trapped charge carriers oppose the applied external field [27]. This plateau further presents some noise and a current spike as a result of a localized breakdown. After all traps are filled, destructive breakdown occurs at nearly $7 \mathrm{MV} / \mathrm{cm}$ for this specimen. The $I-V$ characteristics of the GEE-grown sample is rather poor.

(a)

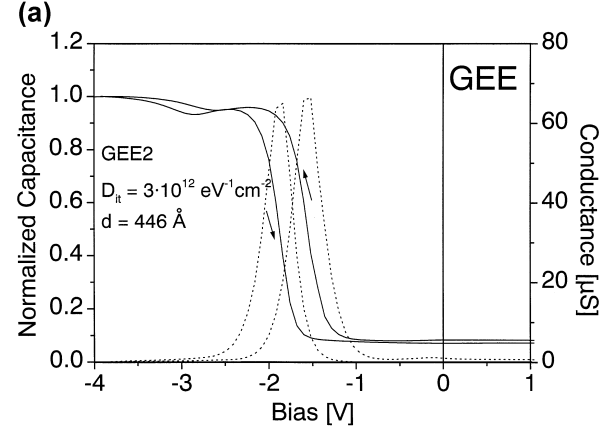

(b)

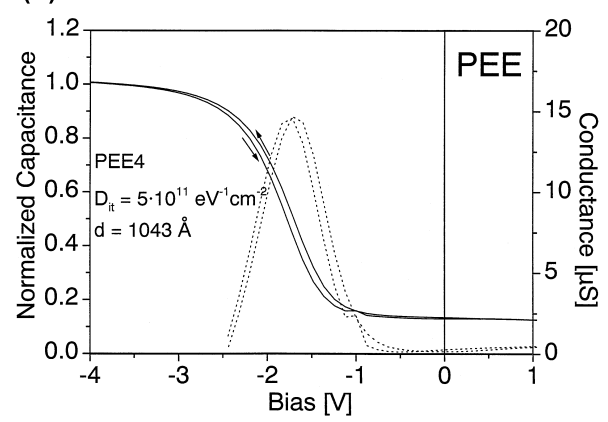

(c)

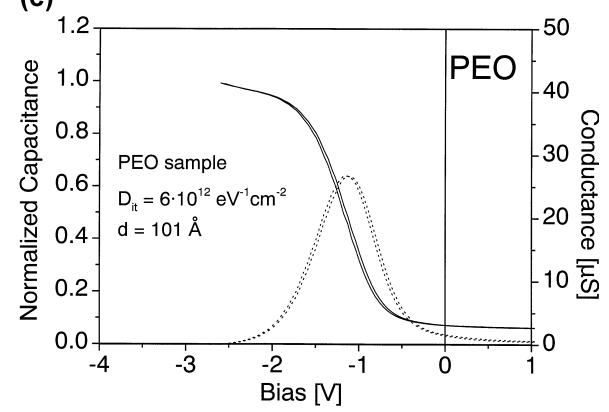

Fig. 14. Trace and retrace $C-V$ characteristics of $\mathrm{SiO}_{2}$ grown by (a) GEE, (b) PEE, (c) PEO
High current injection occurs at even very low fields under 2 $\mathrm{MV} / \mathrm{cm}$. The current saturates between $10^{-5}$ and $10^{-4} \mathrm{~A} /$ $\mathrm{cm}^{2}$ until the high breakdown field of $13 \mathrm{MV} / \mathrm{cm}$. There are two effects responsible for the shift of the destructive breakdown to this very high field. First, the high conductance of the oxide reduces the applied external field in the MOS capacitor. Second, the presence of a large number of charge traps and the build-up of new traps provide a high opposing internal field retarding the breakdown. New traps in the dielectric layer during the voltage ramp can originate due to local heating, caused of the high current flow [27].

According to our observations, the electrical characteristics of GEE and PEE oxides hardly depend on the substrate temperature during growth. The $I-V$ curves of PEO samples improve with increasing substrate temperature, however. Fig. 13 shows that significant current injection occurs in films fabricated at room temperature and at $260^{\circ} \mathrm{C}$. In the films produced at 360 and $480^{\circ} \mathrm{C}$ there is no significant leakage current until the breakdown field is reached.

The excellent dielectric strength makes the PEO oxide a very promising candidate for applications like passivation of vertical MBE-grown devices (this was already shown in [28]) or as a high-field dielectric between the control gate and the floating gate in EPROM devices [3]. Furthermore, the $I-V$ characteristics from wafer to wafer are highly reproducible. A PEE oxide of the above-shown $I-V$ curve can be used as a somewhat thicker passivation layer for nano- and microelectronic devices and as an intermetal dielectric below metallic surfaces. The $I-V$ curves are fairly reproducible and can be improved by optimizing the process parameters. The poor bulk resistivity of the GEE sample is not acceptable for most electronic devices where very thin dielectrics are needed. The high current injection and the trapping ledge are fairly reproducible from wafer to wafer. Sometimes the destructive breakdown occurs at very low fields.

Fig. 14a-c compares the trace and retrace high-frequency $C-V$ and $G-V$ curves of the low-temperature oxides. The negative flatband voltage of all dielectrics indicates that positive charge exists either at the interface or within the bulk layer. The hysteresis between the trace and retrace curve of the GEE and PEE sample is caused by the interchange of charge carriers across the silicon-insulator interface. Holes could be emitted from traps in the insulator and trapped in the oxide, or electrons could be emitted from traps in the insulator and transported into Si. Both effects contribute to hysteresis [29]. This observation is consistent with the $I-V$ characteristics where carrier injection even occurs at rather low fields. The very low hysteresis of 0.2 $\mathrm{V}$ and the flatband voltage of only $-1.2 \mathrm{~V}$ indicate low densities of mobile and fixed charges within the PEO oxide layer. This is in accordance with the $I-V$ curve where no trapping ledge occurs before breakdown.

The interface state density $D_{\text {it }}$ lies between the medium $10^{11}$ to low $10^{12} \mathrm{eV}^{-1} \mathrm{~cm}^{-2}$ range for the low-temperature samples. There occurs no change between the measure- 


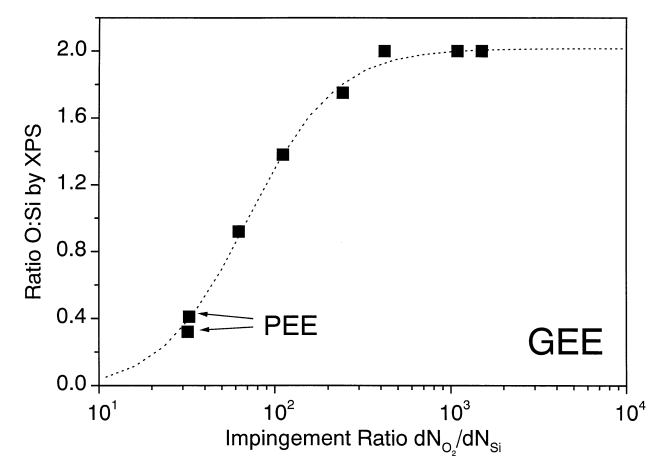

Fig. 15. O:Si ratio in GEE films as a function of the impingement ratio of evaporated silicon and oxygen gas.

ments of the trace and retrace measurement. This is rather poor for applications as gate oxides. Obviously the different growth kinetics for such low temperatures are responsible for the high interface state density. The $D_{\text {it }}$ values of unannealed thermal $\mathrm{SiO}_{2}$ and $\mathrm{CVD}-\mathrm{Si}_{3} \mathrm{~N}_{4}$ are $1.2 \times 10^{11}$ and $2.0 \times 10^{11} \mathrm{eV}^{-1} \mathrm{~cm}^{-2}$, respectively. No postmetallization anneal was performed.

\section{Discussion of film growth}

\subsection{Gas enhanced evaporation (GEE)}

The deposition of $\mathrm{SiO}_{x}$ is performed by reactive evaporation of $\mathrm{Si}$ in $\mathrm{O}_{2}$ atmosphere. $\mathrm{O}_{2}$ naturally reacts with the $\mathrm{Si}$ surface. The composition of the deposited film is supposed to depend on three parameters: the evaporation rate of $\mathrm{Si}$, the oxygen pressure and the wafer temperature. At $\mathrm{O}_{2}$ pressures higher than approximately $2 \times 10^{-2} \mathrm{~Pa}$ the mean free path of the evaporated $\mathrm{Si}$ is lower than the distance between the $\mathrm{Si}$ target and the $\mathrm{Si}$ substrate. Consequently, at pressures lower than $2 \times 10^{-2} \mathrm{~Pa}$ the probability of the formation of molecules like $\mathrm{SiO}$ or even $\mathrm{SiO}_{2}$ through collisions in the gas phase is very small. The chemical reactions take place on the surface of the substrate and later on the growing film, which is exposed to the impingement of Si atoms and molecules as well as to $\mathrm{O}_{2}$ molecules. The particles are adsorbed, reflected, or desorbed after a short contact with the surface. The reaction of the adsorbed species is supported by surface diffusion into the potential wells of the regular lattice sites [30]. Hence, the kinetics of the film growth is controlled by the impingement rates of the participating species, their condensation coefficients and the substrate temperature. The condensation coefficient is the ratio of permanently adsorbed to total impinging particles on the surface. The impingement rates of the evaporant as well as of the reactive gas can be calculated or graphically determined by a nomogram [30] if the gas pressure and the deposition rate with the absence of any gas are known. Fig. 15 describes the dependence of the film composition, i.e. the stoichiometry as determined by XPS, on the impingement ratio of $\mathrm{Si}$ and
$\mathrm{O}_{2}$. It can be clearly seen that $\mathrm{SiO}_{2}$ is obtained if the oxygen pressure is increased beyond a certain value.

A further increase of the impingement ratio can negatively affect the film properties. We observed a decrease of the refractive index down to 1.42 for GEE-grown samples at oxygen pressures far greater than $2 \times 10^{-2} \mathrm{~Pa}$ (Fig. 4). A refractive index lower than the theoretical value of 1.465 (for thermal $\mathrm{SiO}_{2}$ ) is attributed to porousity or low density of the film [31]. Possible reasons are the increased number of collisions and the associated energy loss of the evaporated $\mathrm{Si}$ particles at high gas pressures. Now, molecules like $\mathrm{SiO}$ or $\mathrm{SiO}_{2}$ are likely to hit the surface. The growth of a high quality film (i.e. a film with high density in this case) is impeded by the reduced surface diffusion of rather large species like SiO. Film quality (like electrical performance or film density) could be improved by substrate temperatures higher than $450^{\circ} \mathrm{C}$ leading to enhanced surface diffusion.

The high density of interface states of all oxide samples can also be explained by the film growth kinetics. At low growth temperatures surface migration of adsorbates is suppressed. The Si surface dangling bonds cannot be passivated effectively through chemical bonding. Si dangling bonds usually act as a source of positive fixed charges in the oxide [32]. This can cause problems such as trapping and detrapping of electrons if an electrical field is applied. The electron injection rate is enhanced at high interface state densities because electrons can easily enter the oxide by tunneling when dangling bonds exist at the interface. It was observed by mass spectroscopy that evaporated $\mathrm{Si}$ mainly consists of atomic $\mathrm{Si}$ but also of clusters like $\mathrm{Si}_{2}$ or $\mathrm{Si}_{3}$. Thereby, unoxidized $\mathrm{Si}$ islands are formed in the film which can act as a trap for positive fixed charges when interfacially polarized [33]. For GEE as deposition process, the original $\mathrm{Si}$ surface corresponds to the $\mathrm{SiO}_{2} / \mathrm{Si}$ interface. Hence, the interface properties depend strongly on the $\mathrm{Si}$ surface condition before growth. Special care must be taken with substrate cleaning.

\subsection{Plasma enhanced oxidation (PEO) and plasma enhanced evaporation (PEE)}

For PEO and PEE, two additional plasma-generated reactive species, atomic and negatively charged oxygen $\left(\mathrm{O}^{-}\right)$ [20], as well as an additional gas, Ar, are present, of which the latter is necessary to maintain the discharge. To keep the plasma stable, a minimum of $20 \mathrm{sccm}$ Ar flow, corresponding to $6 \times 10^{-2} \mathrm{~Pa}$, is necessary. At this pressure the mean free path of the evaporated $\mathrm{Si}$ is below but still of the same order of the distance crucible - substrate. Thus, high evaporation rates are necessary to compensate the loss of evaporated Si by scattering with $\mathrm{Ar}$ and $\mathrm{O}_{2}$.

With an arc current of $I_{\text {arc }}=25 \mathrm{~A}$, the arc voltage typically amounts to $U_{\text {arc }}=45 \mathrm{~V}$. The number $N$ of the electrons in the arc is obtained from the relation

$I_{\text {arc }} \cdot t=N \cdot e$ 
where $e$ is the electron charge and $t$ the time. The electrons are emitted from the filament and accelerated over a distance of $50 \mathrm{~cm}$ from the filament to the opposite chamber wall. This yields for the number of electrons

$N=\frac{I_{\mathrm{arc}} \cdot s}{e} \sqrt{\frac{2 m}{e \cdot U_{\mathrm{arc}}}}$

where the electron mass and the distance are represented by $m$ and $s$, respectively. With the arc radius $r$ estimated to 5 $\mathrm{cm}$ the electron density in the arc is calculated as follows

$n=\frac{N}{s \cdot r^{2} \cdot \pi}=1.0 \times 10^{10}\left(\mathrm{~cm}^{-3}\right)$

The density of the present $\mathrm{O}_{2}$ molecules in the chamber is obtained from the ideal gas equation to

$n\left(\mathrm{O}_{2}\right)=\frac{p\left(\mathrm{O}_{2}\right)}{k \cdot T}=4.8 \times 10^{12}\left(\mathrm{~cm}^{-3}\right)$

Here, $p$ is the $\mathrm{O}_{2}$ partial pressure $\left(2 \times 10^{-2} \mathrm{~Pa}\right)$ and $T$ is the temperature, which is supposed to be $300 \mathrm{~K}$.

The growth kinetics of PEO is similar to thermal oxidation and has been previously discussed in brief in this paper. At the beginning of film growth, oxidizing ionic species are transported rapidly by the bias difference between the plasma and the wafer to the interface [20]. The film growth is thus reaction limited. When the layer becomes thicker, the diffusion time reduces the growth speed which is now parabolic (slope (1/2) in Fig. 2). The afore-mentioned difference in bias as well as the small size of atomic $\mathrm{O}$ and ionic $\mathrm{O}^{-}$as compared to molecular $\mathrm{O}_{2}$ are the driving forces for the rapid oxide growth as compared to thermal oxidation. The growth rate of PEO oxides is typically $0.05 \AA / \mathrm{s}$ at $450^{\circ} \mathrm{C}$ for long process times.

The number of atomic oxygen, which is necessary for $\mathrm{SiO}_{2}$ film growth is determined as follows. The oxidation rate $\Phi$ per area of the interface Si atoms is given by

$\Phi(\mathrm{Si})=\frac{\mathrm{d} N_{\mathrm{Si}}}{\mathrm{d} t \cdot \mathrm{d} A}=\frac{\rho_{\mathrm{Si}} \cdot N_{A}}{M_{\mathrm{Si}}} R$

Here, $N_{\mathrm{si}}$ is the number of oxidized $\mathrm{Si}$ atoms at the substate's surface, $t$ is the time of plasma exposure, $A$ is the oxidized area, $N_{\mathrm{A}}$ Avogadro's constant, $M_{\mathrm{Si}}$ is the molecular mass of $\mathrm{Si}(28.09 \mathrm{~g} / \mathrm{mol}), \rho_{\mathrm{Si}}$ the density of crystalline $\mathrm{Si}$ $\left(2.32 \mathrm{~g} / \mathrm{cm}^{3}\right)$, and $R$ is the $\mathrm{SiO}_{2}$ film growth rate, given by film thickness per oxidation time $t$.

With the film growth rate of $0.05 \AA / s$ and taking into account that two oxygen atoms react with one silicon atom of the crystal the following flux of oxygen atoms per time and area towards the Si substrate is necessary

$\Phi(O)=\frac{\mathrm{d} N_{\mathrm{Si}}}{\mathrm{d} t \cdot \mathrm{d} A}=2 \cdot \Phi(\mathrm{Si})=5 \times 10^{13}\left(\mathrm{~s}^{-1} \mathrm{~cm}^{-2}\right)$

With the approximation that the plasma particles exhibit the Maxwell velocity distribution [34] the square root of the mean squared velocity $v$ is given by $\sqrt{\overline{v^{2}}}=\sqrt{\frac{3 \cdot k \cdot T}{m_{\mathrm{O}}}}=6.8 \times 10^{4}(\mathrm{~cm} / s)$

where $m_{\mathrm{O}}$ is the mass of atomic oxygen. For an isotropic velocity distribution only one sixth of the atoms and ions reach the $\mathrm{Si}$ surface and that all of these atoms migrate through the growing film to the substrate, the following density of non-molecular $\mathrm{O}$ species, which can contribute to oxidation is calculated to

$n(\mathrm{O})=\frac{6 \cdot \Phi(\mathrm{O})}{\sqrt{v^{2}}}=4.4 \times 10^{9}\left(\mathrm{~cm}^{-3}\right)$

If this value is compared with the electron density in the arc one can conclude that with our experimental conditions one or two electrons create one pair of atomic $\mathrm{O}$, of which most of them reach the Si substrate by diffusion through the growing film at $450^{\circ} \mathrm{C}$ substrate temperature. Compared with the density of $\mathrm{O}_{2}$ molecules in the chamber, only one over 1000 molecules is dissociated.

Especially, the PEO process buries the $\mathrm{SiO}_{2} / \mathrm{Si}$ interface below the original surface. The interface properties are thus independent of the subsequent oxide formation, but rather depend on the low-rate plasma oxidation process. Thereby, better electrical properties are obtained than by GEE. This can be clearly seen by the low charge carrier injection of the PEO oxides compared to GEE oxides if an external electrical field is applied (Fig. 12).

PEE combines both oxidation methods, GEE and PEO. The film grows by oxidation of the adsorbed $\mathrm{Si}$ on the surface as well as by diffusion of atomic $\mathrm{O}$ into the film. At the beginning of film growth, the interface is buried below the original substrate surface by diffusion of atomic $\mathrm{O}$, known as subcutaneous oxidation. When the film becomes thicker, it is more likely that dangling bonds of $\mathrm{Si}$ rich nano-clusters in the deposited layer serve as a sink for $\mathrm{O}$ radicals. Then, fewer $\mathrm{O}$ species reach the interface. In a word, subcutaneous oxidation is reduced with increasing film growth and with increasing Si content in the deposited film.

It was shown that GEE works well in $\mathrm{O}_{2}$ but not in $\mathrm{N}_{2}$ atmosphere. The reactive Si dangling bonds do not adsorb $\mathrm{N}_{2}$ for its high inertness. Hence, $\mathrm{N}_{2}$ must be dissociated before in the electron arc. However, the PEO oxynitride films grown in an $\mathrm{Ar} / \mathrm{N}_{2}$ plasma without oxygen mainly consist of $\mathrm{SiO}_{2}$ instead of $\mathrm{Si}_{3} \mathrm{~N}_{4}$ and are rather thin compared to PEO oxides grown under the same conditions. This is expected because $\mathrm{Si}_{3} \mathrm{~N}_{4}$ and oxynitrides serve as a diffusion layer for atomic species [35]. During the plasma process, oxygen desorbs from the chamber walls by electron and ion bombardment and is thus always present in the plasma. In addition, the dissociation energy of the inert gas $\mathrm{N}_{2}(9.8 \mathrm{eV})$ is much higher than for $\mathrm{O}_{2}(5.2 \mathrm{eV})$ [36]. This explains why the formation of silicon oxide is much more likely than the formation of silicon nitride even if only $\mathrm{N}_{2}$ is added to the plasma. The sample PEE5 mainly contains silicon nitride 
but is rather silicon rich. The reason is that only very few electrons in the low-energy plasma have enough energy to crack the $\mathrm{N}_{2}$ molecule. Furthermore, if the nitride samples are carried through air to the measurement apparatus, the surface is heavily oxidized by the surrounding air.

\section{Conclusions}

Low-temperature oxides and suboxides were fabricated by the following plasma and evaporation-assisted processes on $\mathrm{Si}$ substrates: gas enhanced evaporation, plasma enhanced oxidation and by a combination of both processes, called plasma enhanced evaporation. The extensive characterization of the films show that stoichiometry is controlled by the impingement ratio of the oxygen and silicon species on the substrate surface for GEE and PEE. PEO is comparable to thermal oxidation because both are diffusion processes. The difference is that $\mathrm{O}$ radicals produced by the plasma migrate much faster through the film than $\mathrm{O}_{2}$ molecules. According to XPS and AES measurements all oxidation states of silicon can be present in the same film depending on the Si:O concentration ratio in the film. The electrical properties are rather determined by the different growth kinetics than by a change of process parameters. The very good $I-V$ characteristics are mainly due to the buried $\mathrm{SiO}_{2} / \mathrm{Si}$ interface. The electrical quality of $\mathrm{SiO}_{2}$ deposited by GEE is rather poor because of low film density and possibly because of incorporated Si rich clusters not detectable by AES or XPS. Due to subcutaneous plasma oxidation, PEE oxides show better electrical properties than GEE films. The low substrate temperature during film growth opens up numerous applications for these processes.

\section{Acknowledgements}

The authors like to thank J. Messarosch, G. Fehlauer, H. Baumgärtner, F. Kaesen, H. Geiger, V.R. Rao and T. Pompl for their assistance in electrical measurements, sample preparation and fruitful discussions. The expertise of $\mathrm{J}$. Ramm, E. Beck and R. Slepicka of Balzers AG is greatfully acknowledged. This work was supported by the BMBF under grant no. BA-672. One of the authors, A. Strass, likes to thank the German Academic Exchange Service (DAAD) for financial assistance during his scientific stay at the Universidad de Chile.

\section{References}

[1] M. Nakamura, Y. Mochizuki, K. Usami, Y. Itoh, T. Nozaki, J. Electrochem. Soc. 132 (1985) 482.

[2] K. Machida, N. Shimoyama, J. Takahashi, N. Yabumoto, E. Arai, IEEE Trans, Electron. Devices 41 (1994) 709.
[3] J. Makwana, B. Grula, D. Monteilh, R. Tyldesley, A. Sorensen, Semiconduct. Int. 10 (1997) 125.

[4] J.H. Magerlein, J.M. Baker, G.R. Proto, K.R. Grebe, S.P. Klepner, M.J. Palmer, A.J. Warnecke, J. Vac. Sci. Technol. B 2 (4) (1984) 636.

[5] N. Chand, et al., J. Cryst. Growth 148 (1995) 336.

[6] D.C. Diaz, C.L. Schow, J. Qi, J.C. Campbell, J.C. Bean, L.J. Peticolas, Appl. Phys. Lett. 69 (19) (1996) 2798.

[7] A. Durandet, A. Perry, R.W. Boswell, et al., Electron. Lett. 32 (4) (1996) 326.

[8] S.K. Ghandhi, VLSI Fabrication Principles, 2nd ed., Wiley, New York, 1993 Chapter 8.

[9] S. Fujita, M. Nishihara, W.L. Hoi, A. Sasaki, Jpn. J. Appl. Phys. 20 (1981) 917.

[10] B.J. Standbery, et al., Solut. Cells 14 (1985) 289.

[11] The National Technology Roadmap for Semiconductors, SIA Semiconductor Industry Association, 1994, p. 103.

[12] H. Gossner, I. Eisele, L. Risch, Jpn. J. Appl. Phys. 33 (1) (1994) 2423.

[13] B. Fowler, E. O'Brien, J. Vac. Sci. Technol. B 12 (1) (1994) 441.

[14] A. Strass, W. Hansch, P. Bieringer, A. Neubecker, F. Kaesen, A. Fischer, I. Eisele, Surf. Coat. Technol. 97 (1997) 158.

[15] W. Hansch, E. Hammerl, W. Kiunke, I. Eisele, J. Ramm, E. Beck, Jpn. J. Appl. Phys. 33 (1) (1994) 2263.

[16] J. Ramm, E. Beck, A. Dommann, I. Eisele, D. Krüger, Thin Solid Films 246 (1994) 158.

[17] L.E. Davis, N.C. MacDonald, P.W. Palmberg, G.E. Riach, R.E. Weber, Handbook of Auger Electron Spectroscopy, Physical Electronics Industries, Eden Prairie, 1976.

[18] B.E. Deal, A.S. Grove, J. Appl. Phys. 36 (1965) 3770.

[19] I. Brodie, J.J. Muray, The physics of Microfabrication, Plenum, New York, 1982.

[20] Y.Z. Hu, Y.Q. Wang, M. Li, E.A. Irene, J. Vac. Sci. Technol. A 4 (11) (1993) 900.

[21] J.F. Moulder, W.F. Stickle, P.E. Sobol, K.D. Bomben, Handbook of XPS, Physical Electronics Industries, Eden Prairie, 1992.

[22] R. Alfonsetti, L. Lozzi, M. Passacantando, P. Picozzi, S. Santucci, Appl. Surf. Sci. 70/71 (1993) 222.

[23] J.R. Shallenberger, J. Vac. Sci. Technol. A 14 (3) (1996) 693.

[24] H. Niwano, Y. Katakura, Y. Takeda, N. Takakuwa, M. Myamoto, J. Vac. Sci. Technol. A 9 (1991) 195.

[25] P.G. Pai, S.S. Chao, Y. Takagi, G. Lucovsky, J. Vac. Sci. Technol. A 4 (1986) 689.

[26] D.V. Tsu, G. Lucovsky, B.N. Davidson, Physical Rev. B 40 (1989) 1795.

[27] D.J. DiMaria, R. Ghez, D.W. Wong, J. Appl. Phys. 51 (9) (1980) 4830.

[28] A. Strass, W. Hansch, F. Kaesen, G. Fehlauer, P. Bieringer, A. Fischer, I. Eisele, 7th Int. Symp. Si MBE, Thin Solid Films, 321 (1998) 261--264.

[29] T.L. Chu, J.R. Szedon, C.H. Lee, Solid State Electron. 10 (1967) 897.

[30] L.I. Maissel, R. Glang, Handbook of Thin Film Technology, McGraw-Hill, New York, 1970.

[31] T.V. Herak, T.T. Chau, D.J. Thomson, S.R. Mejia, D.A. Buchanan, J. Kao, Phys. 65 (6) (1994) 2457.

[32] Y.-B Park, J.-K. Kang, S.-W. Rhee, Thin Solid Films 280 (1996) 43.

[33] P. Dimitrakis, G.J. Papaioannou, J. Appl. Phys. 80 (3) (1996) 1605.

[34] M. Konuma, Film deposition by plasma techniques, Springer-Verlag, Berlin, 1992.

[35] B.E. Deal, E.L. McKenna, P.L. Castro, J. Electrochem. Soc.: Solid State Sci. 116 (7) (1969) 997.

[36] Chemical Rubber Company, CRC Handbook of Chemistry and Physics, 73rd ed., 1993. 